\title{
Variation in resistance to the invasive crayfish plague and immune defence in the native noble crayfish
}

\author{
Christina Gruber ${ }^{1, \star}$, Raine Kortet ${ }^{2}$, Anssi Vainikka ${ }^{2}$, Pekka Hyvärinen ${ }^{3}$, \\ Markus J. Rantala ${ }^{4}$, Ari Pikkarainen ${ }^{4}$, Japo Jussila ${ }^{5}$, Jenny Makkonen ${ }^{5}$, \\ Harri Kokko ${ }^{5}$ \& Heikki Hirvonen ${ }^{1}$
}

1) Integrative Ecology Unit, Department of Biosciences, P.O. Box 65, Fl-00014 University of Helsinki, Finland ("corresponding author's e-mail: christina.gruber@helsinki.fi)

2) Department of Biology, University of Eastern Finland, P.O. Box 111, Fl-80101 Joensuu, Finland

3) Finnish Game and Fisheries Research Institute, Kainuu Fisheries Research, Manamansalontie 90, Fl-88300 Paltamo, Finland

4) Department of Biology, Fl-20014 University of Turku, Finland

5) Department of Biology, University of Eastern Finland, P.O. Box 1627, FI-70211 Kuopio, Finland

Received 23 Apr. 2013, final version received 26 July 2013, accepted 24 July 2013

Gruber, C., Kortet, R., Vainikka, A., Hyvärinen, P., Rantala, M. J., Pikkarainen, A., Jussila, J., Makkonen, J., Kokko, H. \& Hirvonen, H. 2014: Variation in resistance to the invasive crayfish plague and immune defence in the native noble crayfish. - Ann. Zool. Fennici 51: 371-389.

Emerging diseases, such as the crayfish plague, are a worldwide problem with serious ecological and economic impacts. Under the framework of ecological immunology, we investigated whether variation in crayfish plague resistance, the indicators of immune defence (encapsulation response, phenoloxidase and lytic activity), and the exploration behaviour among four subpopulations of noble crayfish is explained by potential local adaptation through differences in crayfish plague history, or alternatively by geographical divergence in a large watershed. We examined whether the strength of immune defence is associated with survival and exploration behaviour. Survival time after experimental crayfish plague infection and phenoloxidase activity differed among the subpopulations of the watershed but did not reveal local adaptation to the disease. Increased investment in immune defence (i.e. encapsulation response) compromised survival time after infection, suggesting the self-reactivity costs of mounting a strong immune response. Exploration behaviour was negatively associated with phenoloxidase activity before and after immune challenge.

\section{Introduction}

Evolving and maintaining parasite resistance and variation in immune defence are essential for host population persistence, since parasites and pathogens can reduce host growth, reproductive success and survival prospects (Goater \& Holmes 1997, Zuk \& Stoehr 2002). Due to a long co-evolutionary history, parasites often show low virulence and host populations high levels of resistance (see Schmid-Hempel 2011). In contrast to local, familiar parasites, nonnative parasites are often highly virulent, causing heavy host mortality and population crashes, as observed in fish and crayfish (Bakke \& Harris 1998, Bangyeekhun 2002, Edgerton et al. 2004). 
The evolvability of resistance or tolerance is a key mechanism for understanding and forecasting the dynamics of host populations in response to emerging diseases caused by non-native parasites and pathogens. Host genetic diversity in immune defence can play an important role in evolving resistance in a population (Altizer et al. 2003). The evolution of resistance should be favoured when parasites and pathogens pose a strong selection pressure on hosts but is only possible when some of the hosts survive and remain able to reproduce (Duncan \& Little 2007, Duffy \& Forde 2009). Recent studies have shown that disease resistance against pathogens in Drosophila melanogaster can evolve in less than ten generations under laboratory conditions (Ye et al. 2009), and natural populations of Daphnia magna planktonic crustaceans are able to evolve immune defence in less than a decade (Pauwels et al. 2010). Whether hosts in the wild can evolve fast enough in response to emerging diseases is still uncertain. Emerging diseases resulting from the introduction of non-native parasites and pathogens are often well documented and offer the opportunity to investigate evolutionary processes, such as the evolving resistance and immune defences of the new host in the wild. Nevertheless, little research has considered local adaptation and geographical variation of native host resistance to emerging diseases, especially in aquatic invertebrates (Penczykowski et al. 2011).

The emerging field of ecological immunology examines the source and consequences of variability in immune defence in natural populations (Rolff \& Siva-Jothy 2003, Schmid-Hempel 2011). Major hypotheses in ecological immunology are that host resistance and investment in immune defences are energetically costly (Zuk \& Stoehr 2002, Schmid-Hempel 2011) and are often traded-off against other fitness-related traits, such as growth and fecundity, leading to resource allocation conflicts (reviewed in Schmid-Hempel 2011). Selection for stronger resistance and an increased energy allocation to immune defences might therefore reduce the allocation to other energetically costly traits including energy demanding behaviours, such as activity and exploration. Recently, associations between immune defence and these behaviours have been specifically highlighted (e.g. Kortet et al. 2007, 2010). The fitness consequences of individuals with consistent differences in such behaviours may depend, however, on disease pressure and other features of the environment (Biro \& Stamps 2008). Still, empirical evidence of trade-offs between energy-demanding behavioural properties and immune defence from natural animal populations are scarce.

The crayfish plague, caused by Aphanomyces astaci, is one of the most striking examples of emerging diseases due to host switching (Edgerton et al. 2004, Peeler \& Feist 2011, Makkonen et al. 2012a). Aphanomyces astaci, a fungus-like pathogen that belongs to the class of Oomycetes, as far as known only infects crayfish (Unestam 1972, Oidtmann et al. 2002, Diéguez-Uribeondo et al. 2009, Makkonen 2013). During the acute stage of the disease, paralysis of the abdomen is often the only visible symptom, which occurs one to two days prior to death (Unestam \& Weiss 1970, Makkonen 2013). The neurotoxic effects of the oomycete are presumably the major cause of death in the crayfish (Nybelin 1934, Schäperclaus 1954, Makkonen 2013). Other reported symptoms are uncoordinated movements, which are described as walking on stilts, combined with spasmodic limb tremor and tail movements (Schikora 1906, Makkonen 2013). As a consequence of the epidemics, the native European noble crayfish Astacus astacus is facing a high risk of extinction in the wild (Red List Category \& Criteria: Vulnerable A2; IUCN Red List of threatened species) and therefore $A$. astaci is being listed among the 100 worldwide worst invasive species (Lowe et al. 2004). The remaining European native crayfish populations, including noble crayfish, differ in their experience of crayfish plague infections, varying from acute disease epidemics to pristine populations without a known history of outbreaks (Jussila et al. 2011b, Kokko et al. 2012, Makkonen et al. 2012b). Understanding of the dynamics of crayfish plague epidemiology is still ambiguous (Fürst 1995, Edgerton et al. 2004). Until recently, there was no empirical evidence of a latent crayfish plague infection in the noble crayfish. However, recent studies have demonstrated that the noble crayfish can actually carry certain strains of the disease without acute symptoms or 
mortality (Jussila et al. 2011b, Viljamaa-Dirks et al. 2011). This indicates that individual- and population-specific differences in disease resistance potentially play a role in the crayfish plague dynamics (Makkonen et al. 2012b) and have prolonged the existence of the disease in certain waters. Furthermore, there are recent reports on population recoveries after crayfish plague epidemics among the Turkish narrow clawed crayfish populations (Harlioğlu 2008, Kokko et al. 2012, Svoboda et al. 2012). These crayfish carry the infection and are commercially exploited despite the lack of a long co-evolutionary history with A. astaci.

Like other invertebrates, crayfish depend on the cellular and humoral components of the innate immune system, including the prophenoloxidase enzyme system with its active form phenoloxidase (PO), the encapsulation response and antimicrobial peptides, such as those producing lytic activity, which enable them to respond to microbial surface antigens (Iwanaga \& Lee 2005, Vazquez et al. 2009). Cerenius et al. (2003) demonstrated that an activated PO system, e.g. due to $\beta$-glucan injection, at the time of exposure can prolong acute crayfish plague infections in the noble crayfish. They suggested that the capacity for producing high prophenoloxidase transcript levels is an effective defence mechanism against $A$. astaci (Cerenius et al. 2003).

Our main aim was to examine whether there is variation in survival time after experimental infection with $A$. astaci, the indicators of immune defence (encapsulation response, PO and lytic activity), and the exploration behaviour of wild-caught noble crayfish either due to (1) local adaptation, i.e. differences in selection caused by disease history (no epidemics experienced $v s$. epidemics experienced) or (2) environmental variation, i.e. differences among four geographically separated subpopulations within one watershed. We predicted that the noble crayfish subpopulations having experienced crayfish plague infections in the past would have been selected for stronger resistance towards the disease and therefore survive longer after experimental infection than subpopulations without disease history. Selection for stronger resistance at the population level through increased energy allocation to immune defences is expected to lower allocation to other energetically costly traits, such as exploration behaviour. We also examined whether crayfish from the four subpopulations had a latent infection by determining the current presence or absence of the disease in the studied subpopulations using PCR analysis (Vrålstad et al. 2009, Jussila et al. 2011b, Strand et al. 2011). Geographical variation in immune defence or exploration behaviour among the four subpopulations originating from different parts of the watershed might represent the effect of variation in environmental factors, such as predation pressure, on their phenotype. As a secondary aim, we investigated whether survival time after experimental crayfish plague infection is linked to the strength of their immune defence. Investment in immune defence, such as PO activity and encapsulation intensity, was predicted to increase survival time after experimental infection. Finally, we examined whether the strength of immune defence was associated with exploration behaviour.

\section{Material and methods}

\section{Study area and crayfish}

We used noble crayfish from four subpopulations within the Oulujoki watershed (OW), which is located in northern Finland (see Fig. 1), and a cultured (ESeppä) population. In Finland, the noble crayfish lives on the northern edge of its distribution and has also been introduced to northern non-native areas such as OW (Skurdal et al. 1999, Souty-Grosset et al. 2006). Noble crayfish introductions started there during the end of the 1800s and peaked from 1926 to 1964 (Ylitalo 1984). The first crayfish plague epidemic in OW was recorded in 1962, and another from 1981 to 1983, which also reached Oulujärvi (Ylitalo 1984), although the origin of the epidemic is unknown. We selected the geographically separated noble crayfish subpopulations based on the knowledge of their crayfish plague history. The two downstream subpopulations, Vaala and Kaivannonsalmi, both in the large Oulujärvi, experienced crayfish plague infections and subsequent recoveries on several occa- 


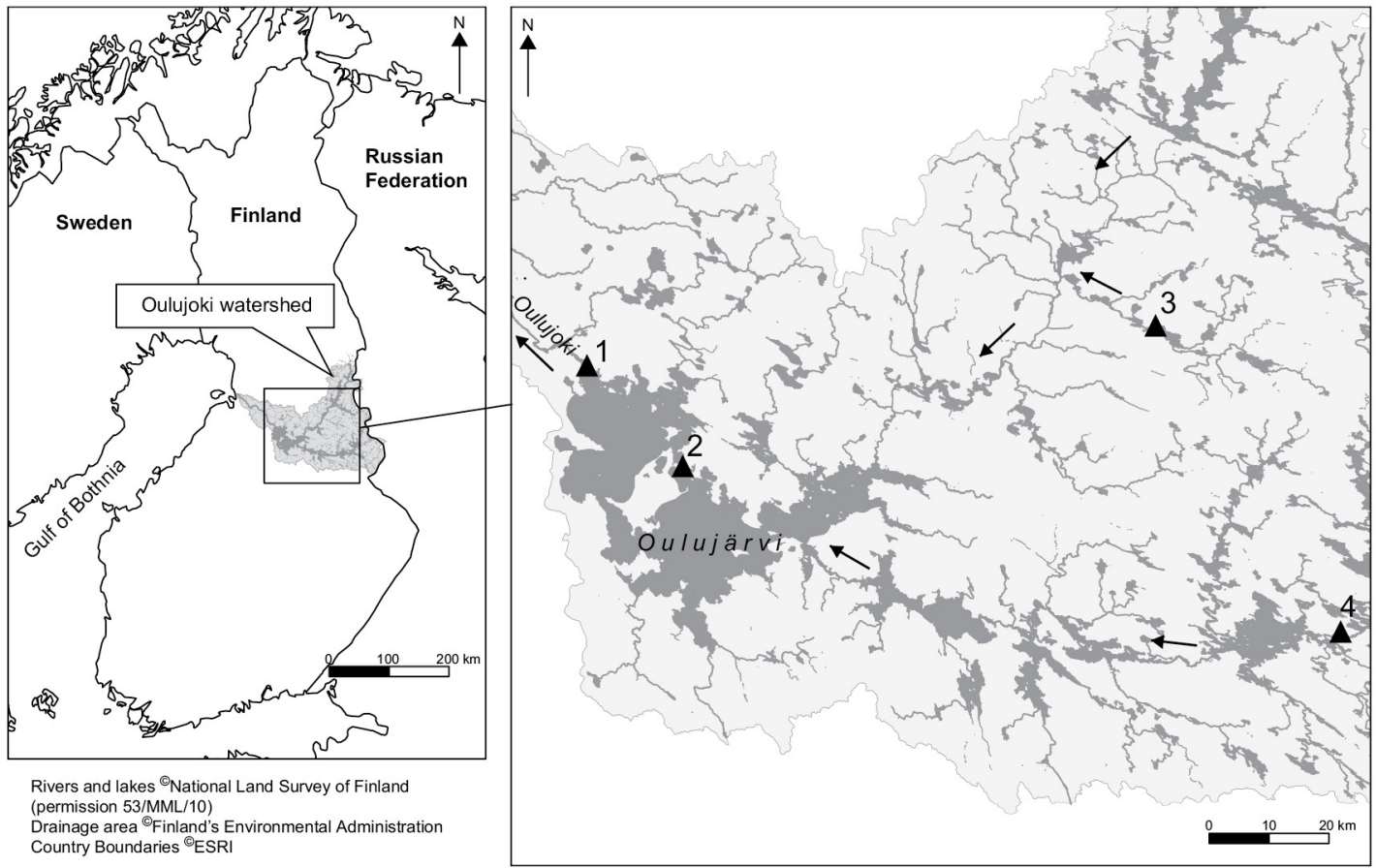

Fig. 1. Map of OW and the origin of the subpopulations: $1=$ Vaala (Oulujärvi), $2=$ Kaivannonsalmi (Oulujärvi), $3=$ Luvanjärvi and 4 = Pajakkakoski (Pajakkajoki). The arrows indicate the direction of the water flow.

sions over the last decades (Ylitalo 1984, Pasi Korhonen, personal communication). Prior to our study, the two upstream subpopulations of Luvanjärvi and Pajakkakoski (Pajakkajoki) were pristine without recorded crayfish plague outbreaks (P. Korhonen pers. comm.).

We obtained the noble crayfish alive from commercial fishermen, who used traps to collect them from the wild during July and August 2009. In total, we used 202 crayfish [ 78 females, mean body mass $27.3 \pm 5.2 \mathrm{~g}(\mathrm{SD})$, and 124 males, mean body mass $31.0 \pm 5.9 \mathrm{~g}(\mathrm{SD})]$ for the immunological, behavioural and infection experiments (Table 1). Additionally, to determine crayfish plague carrier status, 50 cray- fish from each subpopulation were killed by freezing and stored frozen. We used those for the later molecular detection of potential latent infection carriers in the subpopulations. Furthermore, from each subpopulation we examined ten individuals that died during the experiments to determine whether their death was caused by the crayfish plague.

We obtained the cultured population from a commercial supplier (Eino Seppä from Haapajärvi, Northern Bothnia, Finland) on 11 September 2009 and used it as a control population (ESeppä) in the crayfish plague infection experiment. These crayfish had been raised in a 20 ha purpose-built extensive earth-pond system with

Table 1. Details on the wild-caught noble crayfish (A. astacus) used in the experiments.

\begin{tabular}{llccc}
\hline Subpopulation & $n$ & Arrival at lab & Mean mass (g) & Percentage of males \\
\hline Oulujärvi, Vaala & 53 & 3 Aug. 2009 & 27.3 & 60.4 \\
Oulujärvi, Kaivannonsalmi & 54 & 27 Jul. 2009 & 27.2 & 56.6 \\
Luvanjärvi & 49 & 5 Aug. 2009 & 29.8 & 59.2 \\
Pajakkajoki, Pajakkakoski & 46 & 30 Jul. 2009 & 34.8 & 71.7 \\
\hline
\end{tabular}


naturally available food items and grain as additional food. In total, we held 40 ESeppä crayfish [nine females, mean body mass $21.8 \pm 3.1 \mathrm{~g}$ (SD), and 31 males, mean body mass $21.1 \pm 6.1$ $\mathrm{g}(\mathrm{SD})]$ under the same conditions as the crayfish from the wild at the Experimental Unit of the University of Oulu prior to the infection experiment.

\section{Detecting crayfish plague carrier status}

In the laboratory of the University of Eastern Finland, we determined the crayfish plague carrier status of the wild crayfish using TaqMan ${ }^{\circledR}$ PCR, an improved technique to detect $A$. astaci DNA in noble crayfish (Vrålstad et al. 2009). We dissected two uropods and the telson aseptically from the frozen crayfish of the wild subpopulations, pooled them in one sample for each individual and froze them in disposable tubes for subsequent DNA extraction and qPCR analysis (Jussila et al. 2011b). The sample was disrupted in a FastPrep ${ }^{\circledR}$ FP120 (BIO101 Thermo Savant) together with ceramic beads, sterile sea sand (Merck) and DNA extraction kit lysis buffer for $2 \times 30 \mathrm{sec}$ with $6.0 \mathrm{~m} \mathrm{sec}^{-1}$ speed. We extracted DNA using the E.Z.N.A. Insect DNA Isolation kit (Omega Bio-Tek) according to the protocol of the manufacturer. We measured the DNA quantity and quality with a NanoDrop-spectrophotometer (Thermo Fisher Scientific). We performed quantitative TaqMan ${ }^{\circledR}$ MGB PCR as described previously using standard dilutions and threshold values (see Vrålstad et al.2009). Agent level scoring for the detection levels obtained in this study was done according to Vrålstad et al. (2009). A0 represent negative samples, A1 $<5$ PFU (PCR forming units), 5 $\mathrm{PFU} \geq \mathrm{A} 2<50 \mathrm{PFU}, 50 \mathrm{PFU} \geq \mathrm{A} 3<103$ and $103 \geq$ A4 < 104 PFU. An A2 agent level was considered as a reliable but low-level $A$. astaci DNA detection.

\section{Laboratory acclimatization}

The crayfish from OW were brought to the Kainuu Fisheries Research Station within a tenday time-frame (Table 1). To acclimatise them physiologically, we held the crayfish under laboratory conditions for two months prior to any experiments. First we kept the crayfish in 105 $\mathrm{mm}($ width $) \times 145 \mathrm{~mm}$ (length) $\times 200 \mathrm{~mm}$ (water depth) compartments built into two large 12.56 $\mathrm{m}^{2}$ tanks, separating the subpopulations according to their crayfish plague history. We started the fully independent individual holding on 2 September 2009, when the crayfish were moved randomly into individual tanks with independent water inflow $(140 \mathrm{~mm} \times 120 \mathrm{~mm} \times 110 \mathrm{~mm}$ (water level), water flow ca. $0.151 \mathrm{~min}^{-1}$ ). The light-dark rhythm by artificial lighting followed the natural circadian rhythm of the original geographic location of the crayfish. We gave each crayfish carrots ad libitum and a grey plastic tube (length $75 \mathrm{~mm}$, inner diameter $36 \mathrm{~mm}$ ) as shelter. We recorded mortality daily.

\section{Production of $\boldsymbol{A}$. astaci zoospores for the infection experiment}

We used A. astaci strain UEF8866-2 (PsI-genotype), isolated from Puujärvi (Karjalohja, coordinates: N 6683791, E 317391) signal crayfish (P. leniusculus), for zoospore production in the laboratory of the University of Eastern Finland. This strain has been tested and used as a standard reference strain in other infection experiments and is known to be virulent (Jussila et al. 2011a, Makkonen et al. 2012b), thus we considered it suitable for this experiment. We modified the zoospore production method after Cerenius et al. (1988). We cut three pieces (4 $\mathrm{mm}$ in diameter) of mycelia from PG1 agar plate and transferred them into $45 \mathrm{ml}$ of liquid PG1 medium (Unestam 1965) in a sterile 50-ml tube. Altogether we made 24 identical cultures to maximize the spore amount. We incubated the mycelia at room temperature (mean $\pm \mathrm{SD}=20 \pm 2{ }^{\circ} \mathrm{C}$ ) for one week. Then we aseptically cut the mycelia into fragments with a sterile knife on a petri dish, transferred them into a $250 \mathrm{ml}$ Erlenmeyer flask (E-flask) containing $200 \mathrm{ml}$ fresh PG1 medium and incubated the mycelia at room temperature for a week. We filtered the mycelium through a funnel and gauze, transferred it into autoclaved lake water (800 $\mathrm{ml}$ in $11 \mathrm{E}$-flask), and incubated it in a shaker at room temperature for one hour. 
We replaced the autoclaved lake water three times at 1 -hour intervals. The mycelium was then left in the fourth set of lake water and incubated in a shaker for 20 hours at $18{ }^{\circ} \mathrm{C}$. We filtered and pooled the water containing zoospores into a tank and estimated the spore concentration using a Bürker chamber. Spore density in the infection tank system was $23200 \mathrm{ml}^{-1}$.

\section{Experimental crayfish plague infection}

We transported the surviving 46 crayfish (18 females and 28 males) from OW (12 individuals from Vaala, 12 from Kaivannonsalmi, 16 from Luvanjärvi and six from Pajakkakoski), and 40 ESeppä crayfish (nine females, 31 males) from Oulu to the Fish Research Unit of the University of Eastern Finland, Kuopio campus. On 18 December 2009 we conducted the crayfish plague infection experiments to reveal diseaserelated effects and differences in survival time among the subpopulations. We used the ESeppä population as a reference for the wild crayfish that by the time of the infection had undergone a series of experiments, four months of laboratory holding and suffered mortality. The infection tank $(250 \mathrm{~cm} \times 50 \mathrm{~cm} \times 40 \mathrm{~cm})$ was divided into five similar sized sections. Each section, separated by a plastic mesh, was provided with a circulating aquarium pump for aeration and an overabundance of shelters. We placed 18 individually marked noble crayfish in each section in random order. The tank had a flow-through system with a constant $10 \mathrm{~cm}$ water level. We adjusted the sand-filtered water from Kallavesi to $0.51 \mathrm{~min}^{-1}$. We maintained the crayfish at 17.0 $\pm 1.03{ }^{\circ} \mathrm{C}$ (mean $\pm \mathrm{SD}$; range $16-19^{\circ} \mathrm{C}$ ) water temperature and under an 8:16 h light/dark photoperiod during the experiment. The water dissolved oxygen remained above $80 \%$ saturation. We removed dead crayfish daily.

\section{Immunological analyses and treatments}

\section{Encapsulation response}

By implanting a foreign body into the crayfish, we obtained a standardized measure of immune defence. This technique has been used widely and is one of the easiest and most informative ways to determine the strength of immune defence in arthropods (e.g. Yang et al. 2007, van Ooik \& Rantala 2010, Smilanich et al. 2011, Wilson-Rich et al. 2012). In addition to accurately quantifying immune capacity in arthropods, this method especially reveals the resistance of an individual against fungi (Gorman et al. 1996, Rantala \& Roff 2007, but see Rantala et al. 2011). We inserted a nylon monofilament implant (6 $\mathrm{mm}$ long, $0.30 \mathrm{~mm}$ in diameter) in the crayfish to determine the strength of the encapsulation response according to Rantala and Kortet (2004). We first roughened the nylon monofilament (Blue Wing fishing line, Shimano corp. Japan) with sandpaper and then knotted the line before cutting the implants to the desired length. Prior to use we stored the implants in $95 \%$ ethanol to ensure sterility. Additionally to the sterile implants, we used implants that were immersed in 1\% $\beta$-1,3-glucan (from Euglena gracilis, Sigma-Aldrich, product ID \#89862) in crayfish saline ( $\mathrm{pH} \mathrm{7.4,} \mathrm{Hodes} \mathrm{et} \mathrm{al.} \mathrm{2002)} \mathrm{to}$ improve the recognition of the implant by the crayfish immune system. We implanted the crayfish after two months of acclimatization in the Kainuu Fisheries Research Station (14 October 2009). We inserted the implant through a small puncture in the first joint of the cheliped, so that a sterile implant was placed in the left and a $1 \% \beta-1,3$-glucan-treated implant in the right cheliped. We chose this location because the crayfish plague often causes visible melanisation in the joints of infected signal crayfish (Unestam \& Weiss 1970, Nyhlén \& Unestam 1980). We removed the implants 48 hours later and stored them at $-20{ }^{\circ} \mathrm{C}$ for later analysis. The encapsulation response of the 40 ESeppä individuals was measured at the University of Oulu in December using only sterile implants.

In order to quantify the degree of melanisation, we photographed the implants from three different angles using a light microscope and an attached digital camera. We analysed the pictures using the ImageJ program (ver. 1.43u, http:// rsbweb.nih.gov/ij/) to determine the grey values of reflecting light. By calculating the grey value of a clear implant minus the mean of the three grey value measures, we determined the strength 
of the encapsulation response (see Rantala \& Kortet 2004).

\section{Phenoloxidase and lytic activity}

We collected haemolymph samples from each crayfish on three sampling occasions in order to measure phenoloxidase (PO) and lytic activity. On 26 October 2009, we collected the first haemolymph sample from a small puncture in the ventral side of the tail between the third and fourth segment using a micropipette (Finnpipette) with a disposable tip $(10 \mu 1)$. Afterwards, we immune challenged $50 \%$ of the crayfish by injecting $0.1 \mathrm{ml} \mathrm{g}^{-1}$ of $1 \% \beta$-1,3-glucan in crayfish saline (glucan-concentration: $1 \mathrm{mg} \mathrm{ml}^{-1}$ ) using an insulin needle and a Hamilton syringe to mimic a parasite attack and to activate the PO system (Cerenius et al. 2003). As a control for the injection process and wounding, we injected the other group of crayfish with pure crayfish saline. We collected the second haemolymph samples 48 hours after the injections, from a small puncture in the joint of the left cheliped, since the glucan injection was visible in the tail of the crayfish. We employed the same sampling method when collecting the third haemolymph samples 16 days after the injections (11 November 2009). The collected amount of haemolymph was very small compared with the total amount in crayfish. According to our previous experience, this methodological approach, using these multiple immune challenges and injections per animal, does not cause considerable trauma to crayfish. Each haemolymph sample was immediately mixed with $50 \mu 1$ of crayfish saline and frozen at $-80{ }^{\circ} \mathrm{C}$.

For the PO assay, $10 \mu 1$ of the solution (haemolymph mixed with crayfish saline) and $200 \mu 1$ of $10 \mathrm{mM}$ 1-DOPA were thawed and then pipetted into the wells of a 96-well plastic microplate (Cliniplate, Labsystems, Finland). We measured absorbance at $492 \mathrm{~nm}$ spectrophotometrically with a plate reader (EnVision 2103 Multilabel Reader, Wallac, Turku, Finland) at $20{ }^{\circ} \mathrm{C}$ at 1 -min intervals for $30 \mathrm{~min}$. We determined the protein contents of samples with the BioRad protein assay method with a standard curve created from a bovine serum albumin standard. PO activities were expressed as both absolute activities (dAbs $\mathrm{min}^{-1} \mathrm{ml}^{-1}$ ) and as protein-specific activities ( $\mathrm{U} \mathrm{mg}^{-1}$ protein). One unit $(\mathrm{U})$ was the amount of enzyme required to increase the absorbance by $0.001 \mathrm{~min}^{-1}$ (Ruuhola et al. 2010).

We determined lytic activity of haemolymph turbidometrically, using a method modified from Rantala and Kortet (2004): $200 \mu 1$ of 0.35 $\mathrm{mg} \mathrm{ml}^{-1}$ freeze-dried Micrococcus lysoideikticus buffered (pH 6.4) solution was mixed with $50 \mu 1$ of the solution (haemolymph mixed with crayfish saline) and pipetted into the wells of a 96-well plastic microplate (Cliniplate, Labsystems, Finland). We measured the mixture absorbance at $492 \mathrm{~nm}$ at $20^{\circ} \mathrm{C}$ at 1 -min intervals for $30 \mathrm{~min}$ using the plate reader. Lytic activity was quantified as a total change in absorbance and as protein specific lytic activity $\left(\mathrm{U} \mathrm{mg}^{-1}\right.$ protein).

Hereafter, we refer to protein-specific PO or lytic activity analysed from the first sampling occasion as "baseline PO or lytic activity". Protein-specific PO or lytic activity analysed from the second and third sampling occasions are hereafter referred to as " 48 hours and 14 days post-injection".

\section{Behavioural tests}

After collecting the haemolymph samples, we transported the crayfish to the Experimental Unit of the University of Oulu for behavioural experiments. We kept the crayfish individually in 105 $\mathrm{mm}$ (width) $\times 145 \mathrm{~mm}$ (length) $\times 230 \mathrm{~mm}$ (water depth) compartments built in 300-1 tanks. The light-dark rhythm $(9.5 / 14.5 \mathrm{~h})$ and water temperature (mean $\pm \mathrm{SD}=13 \pm 1{ }^{\circ} \mathrm{C}$ ) were kept constant. We fed the crayfish ad libitum with carrot and provided them with a grey plastic tube (length $75 \mathrm{~mm}$, inner diameter $36 \mathrm{~mm}$ ) for sheltering.

We performed a 30-min open-field exploration test for each crayfish individually during 16 November and 16 December 2009. We tested the individuals in haphazard order during the afternoon and evening hours. We placed an individual in a $1300 \mathrm{~mm} \times 180 \mathrm{~mm}$ arena that was floored with sand and filled with standing water (mean $\pm \mathrm{SD}=13 \pm 2{ }^{\circ} \mathrm{C}$ ) to a depth of $200 \mathrm{~mm}$. 
We started the trial by switching off the light and starting the recording of crayfish movement with an infrared camera placed above the arena. After the 30-min trial, we returned the individual to its original holding compartment. Later on, we measured the total distance covered during the trial (hereafter "exploration distance") from the recordings using a custom computer software (AV Bio-Statistics 4.9).

\section{Statistical analyses}

We examined the normality and homoscedasticity of the dependent variables by visual inspection as well as tested them with KolmogorovSmirnov's and Levene's tests. Body mass as well as encapsulation responses were log- and PO activities $\log (x+1)$-transformed in order to meet the assumption of normality and homogeneity of variance. We allowed the violation of statistical normality assumption in baseline PO activity, caused only by a few high values, since separate analyses without them revealed very similar results. Baseline lytic activity was below the detection threshold of the method in 42 out of 181 samples, lytic activity 48 hours post-injection in 35 out of 132 samples and lytic activity 16 days post-injection in 31 out of 99 samples. These values below the detection threshold were included in the data analysis as zeros, since they were equally distributed and separate analyses without them provided very similar results. To meet the assumption of normality, we transformed lytic activity levels using a Box-Cox procedure. We assigned immobile individuals in the behavioural tests as zeros for exploration distance.

We firstly investigated the effect of crayfish plague history on survival time after the experimental crayfish plague infection, and secondly tested between-subpopulation and sex differences in mortality in separate Kaplan-Meier survival analyses with a pairwise Mantel-Cox test. We investigated the associations between survival time and immune defence parameters at the individual level across the subpopulations using a gamma rank-correlation measure $(G)$ for non-normally distributed variables with many tied observations. Variation in body mass among the subpopulations was explored using ANOVA. Furthermore, we investigated the dependence of survival time and other dependent variables on body mass using linear regression. Additionally, we examined differences among the subpopulations in mortality that occurred before the experimental crayfish plague infection was administered in the laboratory. After negative results of the PCR detection, we calculated 95\% confidence intervals for the probability of prevalence in order to estimate the likelihood of $A$. astaci present in the different subpopulations.

To explore the effects of crayfish plague history (with $v s$. without) on encapsulation response to sterile and glucan-treated implants, we ran separate generalised linear mixed models (GLMMs) with crayfish plague history as a fixed factor, subpopulation as a random factor and body mass as a covariate after confirming that the homogeneity of slopes assumption was fulfilled (Enqvist 2005). We employed MANCOVA to examine differences in the strength of the encapsulation responses to sterile and glucantreated implants among the four subpopulations.

Since size had no significant effect on the dependent variables except the encapsulation responses, it was not included in the following final models. We analysed the change between baseline immune defence and immune defence 48 hours post-injection in response to an immune challenge with $\beta$-1,3-glucan or control injection among the crayfish plague history categories using separate GLMMs for PO and lytic activity. We used crayfish plague history, sampling time and their interaction as fixed factors, and subpopulation as well as ID of the crayfish, to take into account the repeated measurements from the same individual, as random factors. For further analysis of the treatment effect, see Appendix 1. To study potential differences in the change between baseline immune defence and immune defence 48 hours post-injection among the subpopulations of OW, we employed RM-ANOVA for PO and lytic activity. Approximately $92 \%$ of the individuals survived at least 16 days after control injection, whereas already $48 \%$ of the crayfish that were injected with $\beta$-1,3-glucan died within two days after the treatment, and overall only $33 \%$ of those glucan-treated individuals survived until the third haemolymph 
sample, taken 16 days post-injection. Since significant mortality occurred between the time of sampling, 48 hours and 16 days post-injection, we conducted separate GLMM and ANOVA for the $\mathrm{PO}$ and lytic activity measures 16 days postinjection. In order to examine whether mortality due to the $\beta-1,3$-glucan injection was selective, we compared the strength of immune defence between the individuals that survived and those that died within a week after the treatment using ANOVA.

To explore differences in exploration distance between the subpopulations with different disease history, we ran GLMM. We employed ANOVA to test for differences in exploration distance among the subpopulations of OW. We used Pearson's correlation $\left(r_{\mathrm{p}}\right)$ for normally distributed data and gamma rank-correlation $(G)$ for non-normally distributed variables with many tied observations to investigate the association between exploration distance and immune defence. All results of those correlations as well as the associations between the immune defence parameters are shown in Appendix 2. We performed all statistical analyses using PASW 18 (SPSS Inc., USA) and AV Bio-Statistics (ver. 4.9).

\section{Results}

\section{Survival time and its association to immune defences}

Three to four days after we added the crayfish plague spores to the rearing tank water, mass mortality started and all the crayfish died after six days (Fig. 2). Kaplan-Meier survival analysis did not reveal a significant effect of crayfish plague history on the survival time of the crayfish (log-rank: $\chi^{2}=2.387$, df $=1, p=$ 0.122 ). However, the average survival time differed significantly among the subpopulations of OW (log-rank: $\chi^{2}=8.735$, df $=3, p=0.033$; including ESeppä: log-rank, $\chi^{2}=12.079$, df $=$ $4, p=0.017$ ) (Fig. 2). Pairwise comparisons indicated that crayfish from the Kaivannonsalmi subpopulation died earlier (mean $\pm \mathrm{SE}=4.08 \pm$ 0.38 days) than crayfish from Vaala $(5.08 \pm 0.15$ days; $p=0.025)$, Luvanjärvi (4.94 \pm 0.30 days; $p$

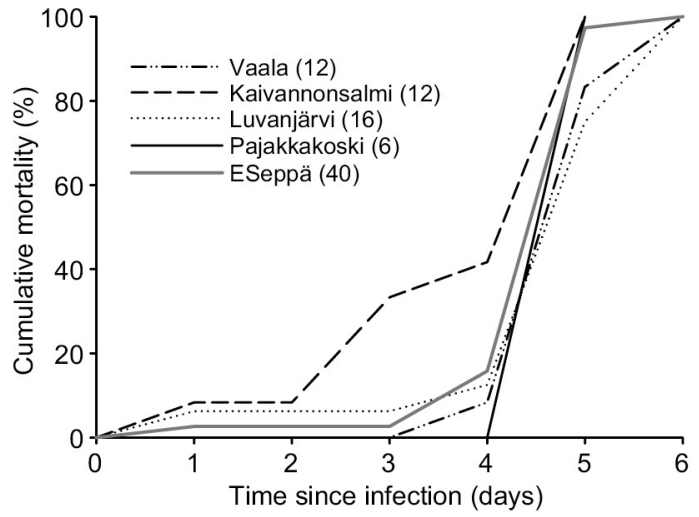

Fig. 2. Cumulative mortality of crayfish from the different subpopulations of $\mathrm{OW}$ and the cultured population under an experimental crayfish plague infection. Sample sizes are shown in parentheses.

$=0.022)$, the cultured population, ESeppä (4.79 \pm 0.12 days; $p=0.028)$ and also tended to die earlier than crayfish from Pajakkakoski (5.0 \pm 0 days; $p=0.078$ ). This result also remains when males are considered separately.

Body mass did not differ among the wild subpopulations (ANOVA: $p=0.115$ ) and was not related to survival time (linear regression, $p=0.644$ ). Females tended to die earlier than males after the crayfish plague infection (Kaplan-Meier survival analysis, log-rank: $\chi^{2}=3.168$, $\mathrm{df}=1, p=0.075)$. Mortality that occurred before the experimental infections in the laboratory differed among the subpopulations of OW (logrank: $\chi^{2}=7.062$, df $\left.=3, p=0.070\right)$, indicating variation in resistance to general stressors. Pairwise comparisons revealed that the crayfish from Kaivannonsalmi subpopulation (mean $\pm \mathrm{SE}=$ $78.82 \pm 3.94$ days) died later than the crayfish from Luvanjärvi $(65.26 \pm 3.51$ days; $p=0.004)$.

Surprisingly, the strength of the encapsulation response was negatively associated with the number of days survived after the infection (encapsulation response to sterile implants: $G$ $=-0.362, n=44, p=0.018$; to glucan-treated implants: $G=-0.375, n=44, p=0.053$; none significant after sequential Bonferroni adjustment). Survival time after the crayfish-plague infection was not correlated with PO or lytic activity of haemolymph $(p \geq 0.218)$. Encapsulation response in the control population ESeppä was not associated with survival time after the 


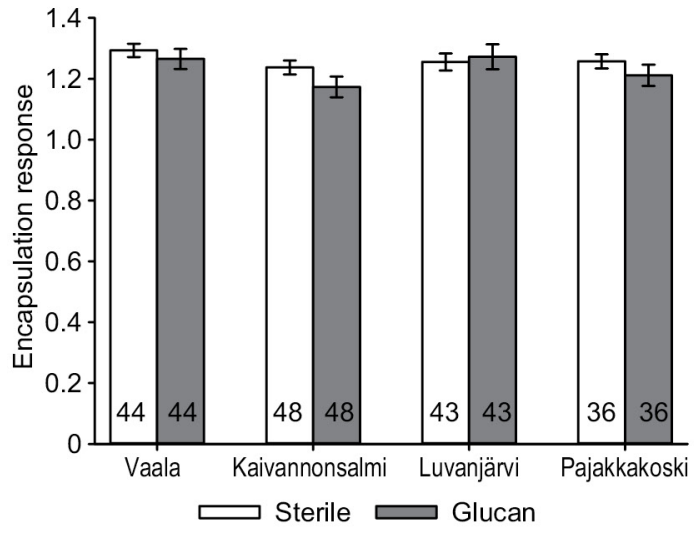

Fig. 3. Estimated marginal means of encapsulation response $( \pm S E)$ with respect to the origin of subpopulations, the treatment of the implant (sterile vs. $\beta$-1,3glucan-treated) and adjusted according to body mass. Sample sizes are shown inside the bars.

crayfish-plague infection $(G=0.077, n=37$, $p=0.655$ ).

\section{PCR detection of $A$. astaci DNA in wild crayfish}

We did not detect any $A$. astaci DNA in the studied crayfish (agent level scoring: A0), which indicated that all our experimental crayfish were free of latent infection. Sixty crayfish tested negative from Vaala, Kaivannonsalmi and Pajakkakoski, with the $95 \%$ CI of $0-0.060$ for prevalence in these subpopulations. From Luvanjärvi 40 individuals tested negative, the $95 \% \mathrm{CI}$ for prevalence was $0-0.088$.

\section{Variation in immune defence}

\section{Encapsulation responses}

The strength of the encapsulation responses to the sterile and the glucan-treated implants were positively related $\left(b=0.369, r^{2}=0.061, t_{169}=\right.$ $3.317, p=0.001)$. According to the results of the GLMM with body size as a covariate, the mean strength of encapsulation response both to the sterile and to the glucan-treated implants did not differ among crayfish plague history categories (sterile implants: $F_{1,171}=1.524, p=0.219$; glucan-treated implants: $F_{1,2}=0.407, p=0.581$ ). However, larger individuals had a stronger encapsulation response (sterile implants: $b=$ $0.221, r^{2}=0.018, F_{1,171}=4.505, p=0.035$; glucan-treated implants: $b=0.358, r^{2}=0.020, F_{1,156}$ $=3.653, p=0.058)$. The mean strength of the encapsulation response did not vary among the subpopulations (MANCOVA: Wilk's $\lambda=0.956$; $F_{6,330}=1.237, p=0.287$; see Fig. 3).

\section{Phenoloxidase activity}

On average, baseline PO activity level (mean \pm $\mathrm{SD}=1.25 \pm 1.82 \mathrm{U} \mathrm{mg}^{-1}$ prot.) was lower than $\mathrm{PO}$ activity levels measured 48 hours $(2.04 \pm 2.08 \mathrm{U}$ $\mathrm{mg}^{-1}$ prot.) as well as 16 days $\left(4.64 \pm 7.04 \mathrm{U} \mathrm{mg}^{-1}\right.$ prot.) after the glucan/control injection. Baseline PO activity was positively related to PO activities measured 48 hours $\left(b=0.271, r^{2}=0.052\right.$, $\left.t_{136}=2.736, p=0.007\right)$ and 16 days post-injection $\left(b=0.318, r^{2}=0.043, t_{102}=2.151, p=0.034\right)$. PO activity levels were not related to body mass (linear regression, $p \geq 0.261$ ). GLMM revealed neither a crayfish plague history effect $\left(F_{1,157}=\right.$ $1.830, p=0.178$ ) nor a significant interaction between sampling time and crayfish plague history $\left(F_{1,145}=1.684, p=0.196\right)$. The change in $\mathrm{PO}$ activity due to immune challenge did not differ among the subpopulations of OW (RM-ANOVA: Wilk's $\lambda=0.982 ; F_{3,134}=0.839, p=0.475, \eta^{2}=$ 0.018). Neither did we detect any differences in mean PO activity measured 16 days postinjection among the crayfish plague history categories (GLMM, crayfish plague history: $F_{1,2}=$ $0.205, p=0.697$ ). However, univariate ANOVA indicated that subpopulation explained significant variation in PO activity measured 16 days postinjection $\left(F_{3,101}=6.857, p<0.001, \eta^{2}=0.169\right)$. Pairwise comparisons $(p \leq 0.007)$ revealed that the crayfish from the Luvanjärvi subpopulation had lower $\mathrm{PO}$ activity (mean $\pm \mathrm{SE}=1.70 \pm 0.32$ $\mathrm{U} \mathrm{mg}^{-1}$ protein) than the crayfish from Vaala $\left(4.42 \pm 0.71 \mathrm{U} \mathrm{mg}^{-1}\right.$ protein), Kaivannonsalmi $\left(4.55 \pm 0.73 \mathrm{U} \mathrm{mg}^{-1}\right.$ protein) and Pajakkakoski $\left(8.33 \pm 3.1 \mathrm{U} \mathrm{mg}^{-1}\right.$ protein) (Fig. 4). Crayfish that died due to the $1 \% \beta$-1,3-glucan immune challenge did not differ in their baseline PO activity from crayfish that survived (ANOVA: $F_{1,172}=$ 1.791, $\left.p=0.183, \eta^{2}=0.010\right)$. 


\section{Lytic activity}

Baseline lytic activity and lytic activity 46 hours post-injection were positively related $(b=0.203$, $\left.r^{2}=0.034, t_{122}=2.057, p=0.042\right)$. Lytic activity was not related to body mass (linear regression, $p \geq 0.204)$. According to the results of GLMM, neither crayfish plague history $\left(F_{1,2}=0.220, p=\right.$ $0.687)$ nor its interaction with sampling time $\left(F_{1,136}=0.128, p=0.721\right)$ had any effect on lytic activity. Repeated measures ANOVA revealed no significant differences among subpopulations and their interactions with sampling time (Wilk's $\lambda=0.993 ; F_{3,120}=0.283, p=0.837, \eta^{2}=0.007$ ). We did not find any differences in mean lytic activity measured 16 days post-injection among the crayfish plague history categories (GLMM, crayfish plague history: $F_{1,97}=0.319, p=0.573$ ). Crayfish that died due to the glucan injection did not differ in their baseline lytic activity from crayfish that survived (ANOVA: $F_{1.170}=0.139$, $\left.p=0.709, \eta^{2}=0.001\right)$.

\section{Behaviour}

In total, 77 crayfish survived until the behavioural tests. On average, the crayfish moved 11.3 $\pm 7.0 \mathrm{~m}$ (mean $\pm \mathrm{SD}$ ). Exploration distance was not related to body mass (linear regression, $p$ $=0.937$ ). Our results did not reveal any differences in exploration distance among the crayfish plague history categories (GLMM: $F_{1.2}=0.175$, $p=0.719$ ), nor among the four subpopulations (ANOVA: $F_{3,73}=1.550, p=0.209, \eta^{2}=0.060$ ).

\section{Association between exploration distance and immune defence parameters}

Exploration distance was negatively associated with both baseline PO activity (Fig. 5a) and PO activity 16 days post-injection (Fig. 5b).

\section{Discussion}

Emerging diseases in freshwater ecosystems have recently received substantial attention (e.g. Peeler \& Feist 2011) but few studies have

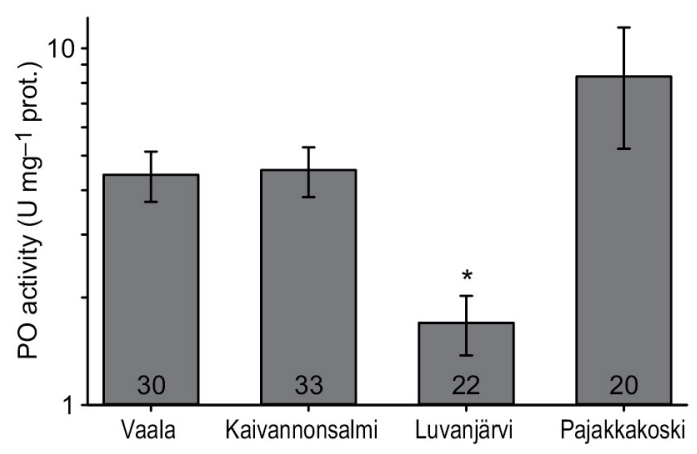

Fig. 4. Variation in immune defence, measured as $P O$ activity sampled 16 days post-injection (mean $\pm \mathrm{SE}$ ), among subpopulations of OW. Star indicates $p<0.01$, sample sizes are shown inside bars. Note log scale used on the y-axis.

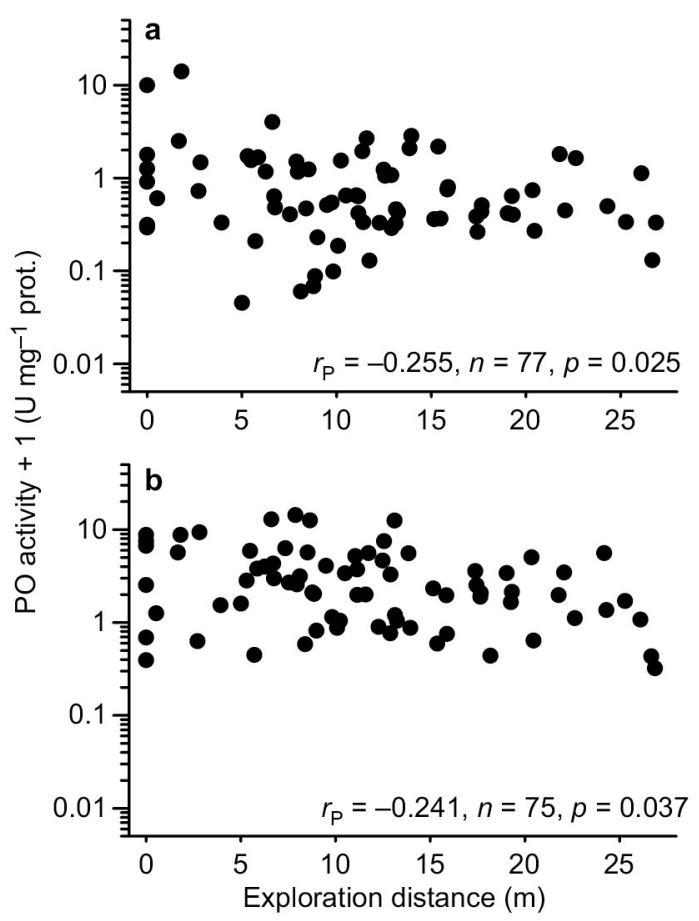

Fig. 5. Pearson's correlations between exploration distance and (a) baseline PO activity, which was measured before the $\beta$-1,3-glucan/control injection, and (b) PO activity measured 16 days post-injection. Note log scale used on the $y$-axis.

investigated the evolution of host resistance and immune defence in response to invasive parasites (Penczykowski et al. 2011). Our results indicate geographic variation in resistance to the crayfish plague and immune defence within 
the Oulujoki watershed but do not reveal clear differences arising from disease-induced local adaptation to the crayfish plague. We also found that increased investment in immune defences (i.e. encapsulation response) compromised survival time after crayfish plague infection. This novel result indicates that the noble crayfish might be vulnerable to the crayfish plague due to the self-reactivity costs of mounting a strong immune response. Furthermore, crayfish exhibiting more exploratory behaviour invested less in their immune defence (i.e. PO activity), indicating a potential resource-allocating conflict between energetically costly immunological and behavioural traits.

\section{Resistance to the crayfish plague and immune defence}

Although the evolution of resistance after an epidemic has been observed in some natural or experimentally-selected populations (Duffy \& Sivars-Becker 2007, Duncan \& Little 2007), the noble crayfish from the pristine (Luvanjärvi and Pajakkakoski) and previously infected (Vaala and Kaivannonsalmi) subpopulations did not differ from each other in mortality after experimental crayfish-plague infection nor in the immune defence parameters (encapsulation, phenoloxidase or lytic activity) and exploration behaviour. Therefore, our results do not reveal clear differences arising from disease-induced local adaptation. According to the records, the first crayfish plague epidemics in Vaala and Kaivannonsalmi occurred approximately 30 years ago (Ylitalo 1984). According to the results of our PCR analyses, the experimental crayfish from all four subpopulations were free of latent infection at the time of sampling. This indicates that currently the disease is also absent from the subpopulations with crayfish plague history. It is known that the zoospores of $A$. astaci can survive and stay infectious for up to two weeks, depending on the water temperature (Unestam 1969, Alderman 2000, Makkonen 2013). Furthermore, repeated zoospore emergence, which allows the zoospore to become encysted and start another motile phase after a short resting period, can occur for at least three times and fur- ther extend the survival of $A$. astaci (Cerenius \& Söderhäll 1984, Makkonen 2013). Based on historic records and recent evidence, demonstrating that the crayfish plague does not necessarily kill all the individuals and that some individuals survive even experimental infections (Jussila $e t$ al. 2011b, Viljamaa-Dirks et al. 2011), it is possible that the experimental crayfish from the subpopulations with disease history were the descendants of individuals that had encountered and survived infections in the past. Another, mutually nonexclusive, possibility is that they were the descendants of individuals that had resided in noninfected areas (e.g. tributaries or isolated areas of the lake) during the past outbreaks and migrated to the studied locations when those were diseasefree. Since we did not find differences among the subpopulations with disease history in the past and the pristine subpopulations, our results may suggest that selection for disease resistance has been relaxed (e.g. McPhee 2003) in the last seven to eight generations, when the crayfish plague had probably been absent.

Although the disease history hypothesis was rejected, we found evidence for geographical variation, independent of crayfish plague history, in survival time after infection as well as in PO activity among the subpopulations. First, the crayfish from Kaivannonsalmi, one of the two subpopulations with disease history, died significantly earlier in the infection experiment than the crayfish from the other subpopulations of $\mathrm{OW}$ as well as the cultured population. There is one plausible explanation for this striking result. It is known that the strength of immune defence and resistance of the host can depend on the genotype of the parasite to which it is exposed to (Carius et al. 2001, Schmid-Hempel \& Ebert 2003). So far, two distinct major $A$. astaci genotypes have been identified in Finland (Vennerström et al. 1998, Makkonen et al.2011), the PsI and As genotypes. Of these two, the As genotype has probably existed longer in Europe and it causes lower mortality (Jussila et al.2011b, Kokko et al.2012, Makkonen et al. 2012b). Most of the crayfish plague outbreaks in northern Finland are caused by the As genotype (Mannonen et al. 2006, Makkonen et al. 2012a). Therefore, it is most likely that the As genotype was responsible for the crayfish plague epidemics in OW. It is thus possible 
that strong selection on immune defences towards the As genotype of the crayfish plague would have resulted in increased resistance toward this specific genotype among the existing crayfish of the Kaivannonsalmi subpopulation. However, in our infection experiment we used the virulent PsI genotype of the crayfish plague, which may not have been present in this watershed. As a result of stronger parasite-mediated directional selection leading to local adaptation of resistance (Duffy \& Forde 2009) toward the As genotype, the crayfish from Kaivannonsalmi may have been less resistant to the novel PsI genotype than crayfish from the other subpopulations. Another explanation for the higher mortality among the Kaivannonsalmi crayfish in the infection experiment could be related to population genetic consequences of high mortality caused by the past severe disease outbreaks. These may have resulted in population bottlenecks leading to reduced genetic variability and lowered fitness (Roff 1997, Frankham et al. 2010) in the wild subpopulation, as genetically homogenous populations often have lower resistance to other diseases (Altizer et al. 2003) such as the PsI genotype in OW. Potential differences in crayfish population dynamics in relation to crayfish plague outbreaks in different parts of OW might also explain why the other subpopulation with crayfish plague history (Vaala) survived longer in the infection experiment than the Kaivannonsalmi crayfish.

In a similar way to survival after infection, one of the subpopulations differed significantly from the others in regard to PO activity. Crayfish from the Luvanjärvi subpopulation had the lowest PO activity as compared with all other subpopulations (Fig. 4), when measured 16 days post-injection and after high mortality occurred. We did not find differences in baseline PO or lytic activity between individuals that died due to the $\beta-1,3$-glucan injection and those that survived, indicating that the surviving crayfish did not differ in their immune defence as compared with those that died due to the treatment. Therefore, the lower PO activity of the Luvanjärvi subpopulation may possibly reflect consequences of geographical separation and/or variation in environmental factors among the subpopulations, although its origin remains unknown. However, although we employed a standard method to quantify PO activity in insects and crayfish (e.g. Ruuhola et al. 2010, Steiger et al. 2011, Ardia et al. 2012), it has to be noted that any interpretations must be done carefully, since this method does not discriminate between spontaneously activated enzyme and remaining proenzyme. Our results suggest that future research should examine potential inter-population variation in resistance of the noble crayfish to the two $A$. astaci genotypes, with emphasis on immunological mechanisms and the significance of epidemic size.

\section{Association between immune defence and resistance to the crayfish plague}

We found a significant negative association between resistance to the crayfish plague and the strength of the encapsulation response in OW. This novel finding clearly contrasts previous evidence in invertebrates indicating that investment in immunity is positively correlated with the strength of resistance (Wilson et al. 2001, see Rolff \& Siva-Jothy 2003). The assumed original host species of $A$. astaci, the signal crayfish $P$. leniusculus, is able to carry the latent infection by encapsulating the parasite (Nyhlén \& Unestam 1980) and by maximising the production of prophenoloxidase transcript levels (Bangyeekhun 2002). The long co-evolution of A. astaci and the signal crayfish probably explains the evolution of an effective immune defence and tolerance of $P$. leniusculus against harm caused by the parasite. However, as indicated by the present data in the noble crayfish, initiating a strong encapsulation response seems to kill the crayfish. This was supported not only by the earlier death of the individuals showing a strong encapsulation response, but also by the high mortality induced by the injection with $\beta-1,3$ glucan. Most likely, the negative association between encapsulation and survival time is due to the self-reactivity costs of a strong immune defence (see Sadd \& Siva-Jothy 2006). The recognition of cell wall components from invading microorganisms, such as $\beta$-1,3-glucan, initiates one of the most important defence mechanisms of invertebrates, the prophenoloxidase (proPO) enzyme cascade, which is involved in the forma- 
tion of melanin, wound healing and the encapsulation of foreign materials (Vazquez et al. 2009, González-Santoyo \& Córdoba-Aguilar 2012). However, during the melanin synthesis, cytotoxic intermediates (including quinones and phenols) are also released, which can cause serious tissue damage (Schmid-Hempel 2011). This kind of self-reactivity cost of immune defences has been previously demonstrated in a beetle, as phenotypic and functional damage of own tissue occurred after an immune challenge (Sadd \& Siva-Jothy 2006).

Cerenius et al. (2003) provided indirect evidence that the capacity for producing a high proPO transcript level might be linked to longer survival after experimental crayfish plague infection in the noble crayfish. They demonstrated that an activated proPO system, e.g. due to the $\beta$-1,3-glucan injections, at the time of the exposure can prolong the acute crayfish plague infection. Unfortunately, due to the glucan-induced mortality we could not test if the glucan-treatment would have increased survival time under experimental infection. Our results nevertheless indicate that survival time after experimental crayfish plague infection was not associated with PO or lytic activity.

\section{Association between immune defence and exploration behaviour}

The noble crayfish from OW that explored a novel environment more had lower PO activity levels before and two weeks after the immune challenge. The overall PO activity increased due to both the $\beta$-1,3-glucan and control injections and was still higher 16 days after the injections as compared with the mean baseline $\mathrm{PO}$ activity. Interestingly, although the PO activity levels increased, the strength of the association between this humoral immune defence and exploration behaviour remained similar (Fig. 5). This suggests that the association is not flexible and that on average the crayfish, independent of their exploration behaviour, increased the strength of their immune defence similarly. Our results may indicate a resource allocation conflict between energetically costly traits, such as investment in immune defence and exploration
(Schmid-Hempel 2011). In vertebrates, behavioural changes are often observed during infections (e.g. Martin et al. 2008). Our results might alternatively represent a similar phenomenon in invertebrates, where sick individuals decrease their behavioural activity. Further studies are needed to unravel the potential underlying mechanisms of the association between immunity and behaviour in invertebrates.

In conclusion, our data provide valuable insights into ecological immunology by examining the extent and potential underlying causes of intra-population level variation in the immune defence of a natural population. Furthermore, our results also provide insights in individuallevel differences by examining the associations between behaviour, immune defence parameters and survival from experimental infections.

\section{Acknowledgements}

This research was funded by the Academy of Finland (project nos. 127398 \& 2608001), the Ministry of Agriculture and Forestry of Finland, the Finnish School in Wildlife Biology, Conservation and Management (LUOVA) and the Emil Aaltonen foundation. We thank the staff of the Experimental Unit of the University of Oulu and the staff in the FGFRI Kainuu Fish Research Station for maintenance of the crayfish and for help in running the experiments. We also thank Aki Puhka and Jani Koskimäki for their help in the experiments, Pasi Korhonen (Metsähallitus) for providing information about the crayfish plague history, Satu Viljamaa-Dirks (Evira) and Pauli Lyytinen (Lekkeri) for encouraging discussions and, finally, Simon Uphill for correcting the English. We are especially grateful to two anonymous referees for their constructive comments and suggestions that helped us to improve the manuscript.

\section{References}

Alderman, D. J. 2000: Summary final report: Effects of exposure to high and low temperatures on the survival of the crayfish plague fungus $A$. astaci in vitro and in vivo. Australian Quarantine and Inspection Service, Canberra.

Altizer, S., Harvell, D. \& Friedle, E. 2003: Rapid evolutionary dynamics and disease threats to biodiversity. Trends in Ecology \& Evolution 18: 589-596.

Ardia, D. R., Gantz, J. E., Schneider, B. C. \& Strebel, S 2012: Costs of immunity in insects: an induced immune response increases metabolic rate and decreases antimicrobial activity. - Functional Ecology 26: 732-739.

Bakke, T. A. \& Harris, P. D. 1998: Diseases and parasites in wild Atlantic salmon (Salmo salar) populations. - 
Canadian Journal of Fisheries and Aquatic Sciences 55: 247-266.

Bangyeekhun, E. 2002: Parasites on crayfish: Characterisation of their pathogenesis, host interactions and diversity. - Ph.D. thesis, Faculty of Science and Technology, University of Uppsala.

Biro, P. A. \& Stamps, J. A. 2008: Are animal personality traits linked to life-history productivity? - Trends in Ecology \& Evolution 23: 361-368.

Carius, H. J., Little, T. J. \& Ebert, D. 2001: Genetic variation in a host-parasite association: Potential for coevolution and frequency-dependent selection. - Evolution 55: 1136-1145.

Cerenius, L., Bangyeekhun, E., Keyser, P., Söderhäll, I. \& Söderhäll, K. 2003: Host prophenoloxidase expression in freshwater crayfish is linked to increased resistance to the crayfish plague fungus, Aphanomyces astaci. - Cellular Microbiology 5: 353-357.

Cerenius, L., Rennie, P. \& Fowke, L. 1988: Endocytosis of cationized ferritin by zoospores of the fungus Aphanomyces euteiches. - Protoplasma 144: 119-124.

Cerenius, L. \& Söderhäll, K. 1984: Repeated zoospore emergence from isolated spore cysts of Aphanomyces astaci. - Experimental Mycology 8: 370-377.

Cotter, S. C., Kruuk, L. E. B. \& Wilson, K. 2004: Costs of resistance: Genetic correlations and potential trade-offs in an insect immune system. - Journal of Evolutionary Biology 17: 421-429

Diéguez-Uribeondo, J., García, M. A., Cerenius, L., Kozubíková, E., Ballesteros, I., Windels, C., Weiland, J., Kator, H., Söderhäll, K. \& Martín, M. P. 2009: Phylogenetic relationships among plant and animal parasites, and saprotrophs in Aphanomyces (Oomycetes). - Fungal Genetics and Biology 46: 365-376.

Duffy, M. A. \& Forde, S. E. 2009: Ecological feedbacks and the evolution of resistance. - Journal of Animal Ecology 78: 1106-1112.

Duffy, M. A. \& Sivars-Becker, L. 2007: Rapid evolution and ecological host-parasite dynamics. - Ecology Letters 10: 44-53.

Duncan, A. B. \& Little, T. J. 2007: Parasite-driven genetic change in a natural population of Daphnia. - Evolution 61: 796-803.

Edgerton, B. F., Henttonen, P., Jussila, J., Mannonen, A., Paasonen, P., Taugbøl, T., Edsman, L. \& Souty-Grosset, C. 2004: Understanding the causes of disease in European freshwater crayfish. - Conservation Biology 18: 1466-1474.

Engqvist, L. 2005: The mistreatment of covariate interaction terms in linear model analyses of behavioural and evolutionary ecology studies. - Animal Behaviour 70: 967-971

Frankham, R., Ballou, J. D. \& Briscoe, D. A. 2010: Introduction to conservation genetics, 2nd ed. - Cambridge University Press, Cambridge.

Fürst, M. 1995: On the recovery of Astacus astacus L. populations after an epizootic of the crayfish plague (Aphanomyces astaci Shikora). - Freshwater Crayfish 8: 565-576.

Goater, C. P. \& Holmes, J. C. 1997: Parasite-mediated natu- ral selection. - In: Clayton, D. H. \& Moore, J. (eds.), Host-parasite evolution: General principles and avian models: 9-30. Oxford University Press, Oxford.

González-Santoyo, I. \& Córdoba-Aguilar, A. 2012: Phenoloxidase: a key component of the insect immune system. - Entomologia Experimentalis et Applicata 142: 1-16.

Gorman, M. J., Cornel, A. J., Collins, F. H. \& Paskewitz, S. M. 1996: A shared genetic mechanism for melanotic encapsulation of CM-Sephadex beads and a malaria parasite, Plasmodium cynomolgi B, in the mosquito, Anopheles gambiae. - Experimental Parasitology 84: 380-386.

Harlioğlu, M. M. 2008: The harvest of the freshwater crayfish Astacus leptodactylus Eschscholtz in Turkey: harvest history, impact of crayfish plague, and present distribution of harvested populations. - Aquaculture International 16: 351-360.

Hodes, K., Aung, M. H. \& Yang, S. 2002: A molting hormone, 20-hydroxyecydsone appears to reduce synaptic efficacy in crayfish fast extensor muscle fibers by binding to the presynaptic glutamate autoreceptors. - Pioneering Neuroscience 3: 45-48.

Iwanaga, S. \& Lee, B. L. 2005: Recent advances in the innate immunity of invertebrate animals. - Journal of Biochemistry and Molecular Biology 38: 128-150.

Jussila, J., Makkonen, J. \& Kokko, H. 2011a: Peracetic acid (PAA) treatment is an effective disinfectant against crayfish plague (Aphanomyces astaci) spores in aquaculture. - Aquaculture 320: 37-42.

Jussila, J., Makkonen, J., Vainikka, A., Kortet, R. \& Kokko, H. 2011b: Latent crayfish plague (Aphanomyces astaci) infection in a robust wild noble crayfish (Astacus astacus) population. - Aquaculture 321: 17-20.

Kokko, H., Koistinen, L., Harlioğlu, M. M., Makkonen, J., Aydin, H. \& Jussila, J. 2012: Recovering Turkish narrow clawed crayfish (Astacus leptodactylus) populations carry Aphanomyces astaci. - Knowledge and Management of Aquatic Ecosystems 404: 12.

Kortet, R., Hedrick, A. V. \& Vainikka, A. 2010: Parasitism, predation and the evolution of animal personalities. Ecology Letters 13: 1449-1458.

Kortet, R., Rantala, M. J. \& Hedrick, A. 2007: Boldness in anti-predation behavior and immune defence in field crickets. - Evolutionary Ecology Research 9: 185-197.

Lowe, S., Browne, M., Boudjelas, S. \& De Poorter, M. 2004: 100 of the world's worst invasive alien species. A selection from the Global Invasive Species Database. - The Invasive Species Specialist Group (ISSG), a specialist group of the Species Survival Commission (SSC) of the IUCN, Gland, Switzerland.

Makkonen, J. 2013: The crayfish plague pathogen Aphanomyces astaci: Genetic diversity and adaptation to the host species. - Ph.D. thesis, Faculty of Science and Forestry, University of Eastern Finland, Kuopio.

Makkonen, J., Jussila, J., Henttonen, P. \& Kokko, H. 2011: Genetic variation in the ribosomal internal transcribed spacers of Aphanomyces astaci Schikora from Finland. - Aquaculture 311: 48-53.

Makkonen, J., Jussila, J. \& Kokko, H. 2012a: The diversity 
of the pathogenic oomycete (Aphanomyces astaci) chitinase genes within the genotypes indicate adaptation to its hosts. - Fungal Genetics and Biology 49: 635-642.

Makkonen, J., Jussila, J., Kortet, R., Vainikka, A. \& Kokko, H. 2012b: Differing virulence of Aphanomyces astaci isolates and the elevated resistance of noble crayfish (Astacus astacus) against crayfish plague. - Diseases of Aquatic Organisms 102: 129-136.

Mannonen, A., Halonen, T., Nylund, V., Westman, K. \& Westman, P. 2006: Raputautirekisteri. Raputautien esiintyminen Suomessa vuosina 1893-2000. - Maa- ja metsätalousministeriö, Helsinki.

Martin, L. B., Weil, Z. M. \& Nelson R. J. 2008: Fever and sickness behaviour vary among congeneric rodents. Functional Ecology 22: 68-77.

McPhee, M. E. 2003: Generations in captivity increases behavioral variance: considerations for captive breeding and reintroduction programs. - Biological Conservation 115: 71-77.

Nybelin, O. 1934: Nya undersokningar over kraftpestens orsak. - Ny Svensk Fiskeritidskrift: 110-114.

Nyhlén, L. \& Unestam, T. 1980: Wound reactions and Aphanomyces astaci growth in crayfish cuticle. - Journal of Invertebrate Pathology 36: 187-197.

Oidtmann, B., Heitz, E., Rogers, D. \& Hoffmann, R. W. 2002: Transmission of crayfish plague. - Diseases of Aquatic Organisms 52: 159-167.

Pauwels, K., De Meester, L., Put, S., Decaestecker, E. \& Stoks, R. 2010: Rapid evolution of phenoloxidase expression, a component of innate immune function, in a natural population of Daphnia magna. - Limnology and Oceanography 55: 1408-1413.

Peeler, E. J. \& Feist, S. W. 2011: Human intervention in freshwater ecosystems drives disease emergence. Freshwater Biology 56: 705-716.

Penczykowski, R. M., Forde, S. E. \& Duffy, M. A. 2011: Rapid evolution as a possible constraint on emerging infectious diseases. - Freshwater Biology 56: 689-704.

Povey, S., Cotter, S. C., Simpson, S. J., Lee, K. P. \& Wilson, K. 2009: Can the protein costs of bacterial resistance be offset by altered feeding behaviour? - Journal of Animal Ecology 78: 437-446.

Rantala, M. J. \& Kortet, R. 2004: Male dominance and immunocompetence in a field cricket. - Behavioral Ecology 15: 187-191.

Rantala, M. J. \& Roff, D. A. 2007: Inbreeding and extreme outbreeding cause sex differences in immune defence and life history traits in Epirrita autumnata. - Heredity 98: 329-336.

Rantala, M. J., Viitaniemi, H. \& Roff, D. A. 2011: Effects of inbreeding on potential and realized immune responses in Tenebrio molitor. - Parasitology 138: 906-912.

Roff, D. A. 1997: Evolutionary quantitative genetics. Chapman \& Hall, New York.

Rolff, J. \& Siva-Jothy, M. T. 2003: Invertebrate ecological immunology. - Science 301: 472-475.

Ruuhola, T., Yang, S. \& Rantala, M. J. 2010: Increase in the substrate availability decreases phenoloxidase activity in the autumnal moth, Epirrita autumnata. - Chemoecology 20: 11-18.
Sadd, B. M. \& Siva-Jothy, M. T. 2006: Self-harm caused by an insect's innate immunity. - Proceedings of the Royal Society B 273: 2571-2574

Schäperclaus, W. 1954: Fischkrankheiten, 3. ed. - Akademie Verlag, Berlin.

Schikora, F. 1906: Die Krebspest. - Fischerei-Zeitung 9: 529-532.

Schmid-Hempel, P. 2011: Evolutionary parasitiology - The integrated study of infections, immunology, ecology and genetics. - Oxford University Press Inc., New York.

Schmid-Hempel, P. \& Ebert, D. 2003: On the evolutionary ecology of specific immune defence. - Trends in Ecology \& Evolution 18: 27-32.

Skurdal, J., Taugbøl, T., Burba, A., Edsman, L., Söderbäck, B., Styrishave, B., Tuusti, J. \& Westman, K. 1999: Crayfish introductions in the Nordic and Baltic countries. - In: Gherardi, F. \& Holdich, D. M. (eds.), Crayfish in Europe as aien species: how to make the best of a bad situation: 193-219. A.A. Balkema, Rotterdam.

Smilanich, A. M., Mason, P. A., Sprung, L., Chase, T. R. \& Singer, M. S. 2011: Complex effects of parasitoids on pharmacophagy and diet choice of a polyphagous caterpillar. - Oecologia 165: 995-1005.

Souty-Grosset, C., Reynolds, J., Gherardi, F., Schulz, R., Edsman, L., Fuereder, L., Taugbøl, T., Noël, P., Holdich, D., Smietana, P., Mannonen, A. \& Carral, J. 2006: Craynet - achievements in scientific management of European crayfish, the way forward and future challenges. - Bulletin Francais de la Peche et de la Pisciculture 380-381: 1395-1405.

Steiger, S., Gershman, S. N., Pettinger A. M., Eggert A.-K. \& Sakaluk, S. K. 2011: Sex differences in immunity and rapid upregulation of immune defence during parental care in the burying beetle, Nicrophorus orbicollis. Functional Ecology 25: 1368-1378.

Strand, D. A., Holst-Jensen, A., Viljugrein, H., Edvardsen, B., Klaveness, D., Jussila, J. \& Vrålstad, T. 2011: Detection and quantification of the crayfish plague agent in natural waters: direct monitoring approach for aquatic environments. - Diseases of Aquatic Organisms 95: 9-17.

Svoboda, J., Kozubíková, E., Kozák, P., Kouba, A., Bahadir Koca, S., Diler, Ö., Diler, I., Policar, T. \& Petrusek, A. 2012: PCR detection of the crayfish plague pathogen in narrow-clawed crayfish inhabiting Lake Eğirdir in Turkey. - Diseases of Aquatic Organisms 98: 255-259.

Unestam, T. 1965: Studies on crayfish plague fungus Aphanomyces astaci. I. Some factors affecting growth in vitro. - Physiologia Plantarum 18: 483-505.

Unestam, T. 1969: Resistance to the crayfish plague in some American, Japanese and European crayfishes. - Report of the Institute of Freshwater Research, Drottningholm 49: 202-209.

Unestam, T. 1972: On the host range and origin of the crayfish plague fungus. - Report of the Institute of Freshwater Research, Drottningholm 52: 192-198.

Unestam, T. \& Weiss, D. W. 1970: The host-parasite relationship between freshwater crayfish and the crayfish disease fungus Aphanomyces astaci: responses to infection by a susceptible and a resistant species. - Journal of 
General Microbiology 60: 77-90.

van Ooik, T. \& Rantala, M. J. 2010: Local adaptation of an insect herbivore to a heavy metal contaminated environment. - Annales Zoologici Fennici 47: 215-222.

Vargas-Albores, F. \& Yepiz-Plascencia, G. 2000: Beta glucan binding protein and its role in shrimp immune response. - Aquaculture 191: 13-21.

Vazquez, L., Alpuche, J., Maldonado, G., Agundis, C., Pereyra-Morales, A. \& Zenteno, E. 2009: Immunity mechanisms in crustaceans. - Innate Immunity 15: 179-188.

Vennerström, P., Söderhäll, K. \& Cerenius, L. 1998: The origin of two crayfish plague (Aphanomyces astaci) epizootics in Finland on noble crayfish, Astacus astacus. - Annales Zoologici Fennici 35: 43-46.

Vetvicka, V. \& Sima, P. 2004: Beta-glucan in invertebrates. - Invertebrate Survival Journal 1: 60-65.

Viljamaa-Dirks, S. Heinikainen, S., Nieminen, M., Vennerström, P. \& Pelkonen, S. 2011: Persistent infection by crayfish plague Aphanomyces astaci in a noble crayfish population - a case report. - Bulletin of the European Association of Fish Pathologists 31: 182-188.

Vrålstad, T., Knutsen, A. K., Tengs, T. \& Holst-Jensen, A. 2009: A quantitative TaqMan (R) MGB real-time polymerase chain reaction based assay for detection of the causative agent of crayfish plague Aphanomyces astaci. - Veterinary Microbiology 137: 146-155.

Wilson, K., Cotter, S. C., Reeson, A. F. \& Pell, J. K. 2001: Melanism and disease resistance in insects. - Ecology Letters 4: 637-649.

Wilson-Rich, N., Tarpy, D. R. \& Starks, P. T. 2012: Withinand across-colony effects of hyperpolyandry on immune function and body condition in honey bees (Apis mellifera). - Journal of Insect Physiology 58: 402-407.

Yang, S. Y., Ruuhola, T. \& Rantala, M. J. 2007: Impact of starvation on immune defense and other life-history traits of an outbreaking geometrid, Epirrita autumnata: a possible causal trigger for the crash phase of population cycle. - Annales Zoologici Fennici 44: 89-96.

Ye, Y. H., Chenoweth, S. F. \& McGraw, E. A. 2009: Effective but costly, evolved mechanisms of defense against a virulent opportunistic pathogen in Drosophila melanogaster. - Plos Pathogens 5(4), e1000385, doi:10.1371/ journal.ppat.1000385.

Ylitalo, A. 1984: Oulun läänin raputalouden elvytys. Oulun kalastuspiiri.

Zuk, M. \& Stoehr, A. M. 2002: Immune defense and host life history. - American Naturalist 160: S9-S22. 


\section{Appendix 1. Activation of immune defence and the role of $\beta-1,3$-glucan}

In order to investigate the change in immune defence in response to $\beta-1,3$-glucan or control injection, we ran separate GLMMs for PO and lytic activity. Baseline and immune defence 48 hours post-injection were used as dependent variable, glucan/control treatment, sampling time and their interaction as fixed factors, and subpopulations as well as ID of the crayfish, to take into account the repeated measurement, were used as random factors.

The results of the GLMM revealed a significant sampling time effect $\left(F_{1,147}=31.141\right.$, $p<0.001)$ as well as a significant interaction between sampling time and injection treatment (control vs. glucan) $\left(F_{1,147}=6.477, p=0.012\right)$, indicating that $\mathrm{PO}$ activity levels increased between the sampling times but so that in the control treatment the increase was steeper than in the glucan-treated crayfish (Fig. A1). The treatment had no effect on PO activity 16 days postinjection (GLMM: $F_{1,102}=0.106, p=0.745$ ).

Neither could we detect a significant treatment effect on lytic activity (GLMM: $F_{1,152}=$ $1.071, p=0.302)$, nor was the interaction with the sampling time significant $\left(F_{1,136}=0.182, p=\right.$ $0.670)$. However, lytic activity during the second sampling time was significant lower compared to the first $\left(F_{1,136}=5.970, p=0.016\right)$. The treatment had no effect on the lytic activity 16 days postinjection (GLMM: $F_{1,97}=0.943, p=0.334$ ).

Baseline levels of immune defence might not necessarily indicate the strength of an activated immune response. Therefore, in order to get biologically more meaningful encapsulation response and PO activity results, we used $\beta-1,3-$ glucan because of its role in the initiation of

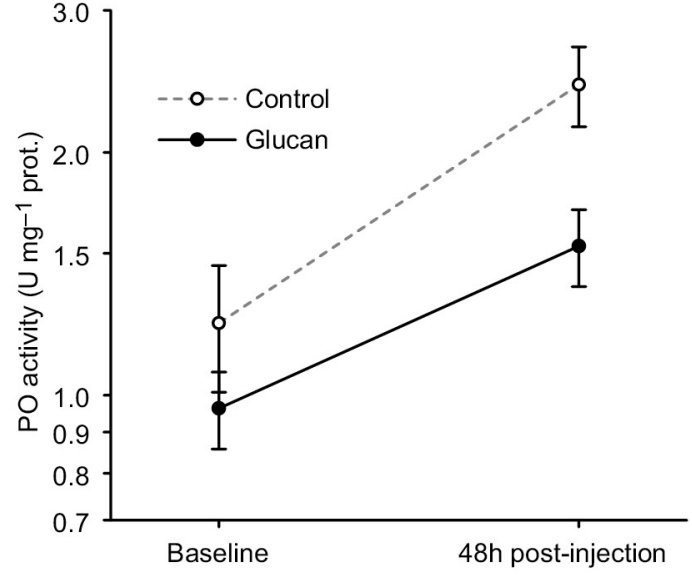

Fig. A1. Variation in the response of the immune defence, measured as protein specific PO activity (mean $\pm \mathrm{SE}$ ), to an immune challenge with a control or $\beta-1,3-$ glucan injection. Note log scale used on the $y$-axis.

the prophenoloxidase enzyme system (VargasAlbores \& Yepiz-Plascencia 2000, Vetvicka \& Sima 2004, Vazquez et al. 2009). Our results support previous findings (Cerenius et al. 2003), showing that $\mathrm{PO}$ activity levels increased due to both injections (probably due to wounding) but revealed a stronger response to the control rather than the glucan treatment (Fig. A1). An explanation for this finding could be trade-offs between PO activity and other major immunological components, for example lytic activity induced by antibacterial peptides (Cotter et al. 2004, Povey et al. 2009). However, we did not find evidence that variation in lytic activity was explained by the $\beta$-1,3-glucan or control injections. 


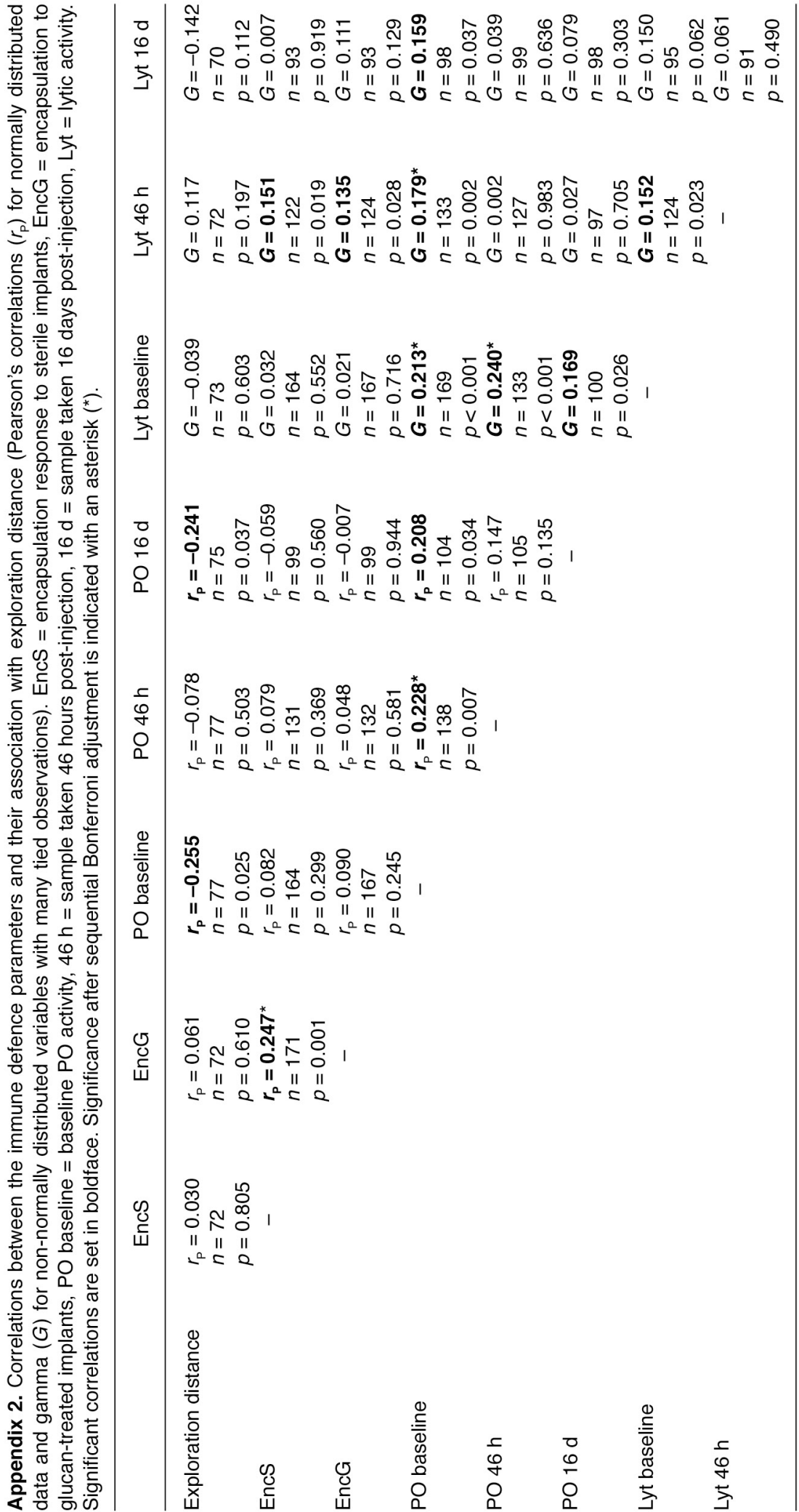

